\title{
Progress towards Employment Equity in Institutions of Higher Education in South Africa
}

\author{
Malose Isaac Kola \\ University of Limpopo \\ Email:malosekola@yahoo.com
}

\section{Stephanus Gert Pretorius}

University of South Africa

Email: pretosg@unisa.ac.za

\section{Doi:10.5901/mjss.2014.v5n20p1316}

\section{Abstract}

This article aimed at investigating the progress made with the problem of Employment Equity (EE) in higher education institutions since the new education dispensation was launched in 1994. South African universities have embarked upon a wide range of initiatives to foster and acclimatise to new social development needs. However, it was found that the composition of staff in higher education institutions failed to reflect the demographic realities of South Africa, with the result that black people and women were still severely under-represented, especially in senior academic management positions. Quantitative research methods were employed to collect data from the academic managers of the University of Pretoria, University of Witwatersrand, and Free State University. The study concluded that white males were still dominating in managerial positions of selected universities and white females were adequately represented, particularly in the professional and academic categories.

Keywords: equity; employment equity; affirmative action; diversity

\section{Introduction}

After the change to a democratic dispensation in 1994 higher education institutions in South Africa were mandated to conform to social and economic imperatives (Ntshoe, 2003). Higher education was purported to be a springboard for the establishment of an impartial and democratic society (Ramrathan, Manik \& Pillay, 2007). Because higher education plays a pivotal role in socio-economic development, higher education institutions in South Africa were faced with the challenge to eradicate historical imbalances and realign their programmes to serve the putative new social order (Department of Education (DoE), 1997).

In an attempt to eradicate past inequities in South Africa, affirmative action was approved to promote equal opportunity and fair treatment. The main purpose of affirmative action was to advance members of the designated groups, namely black people, women and people with disabilities (Thomas, 2003). The Employment Equity Act (EEA) of 1998 was introduced to establish a more equitable workplace in South Africa. The purpose of the EEA was to achieve the objectives of affirmative action, that is, to achieve equity in the workplace by eliminating unfair discrimination and promoting equal opportunity and fair treatment. The Act has important implications for higher education institutions.

All higher education institutions were required to review their existing policies and draft an employment equity (EE) plan (Portnoi, 2009). Thus, South Africa's political and social transformation has prompted higher education institutions to develop their respective transformation programmes based on the principles of democracy, equity, and social justice. Several higher education institutions have already advanced on equity and diversity while others are lagging behind (Cassim, 2005).

It was evident from a review of the annual report provided by the Department of Labour (DoL) (2010) on the progress made by selected institutions of higher education that $40 \%$ of the top management team of the University of the Free State was made up of whites and coloureds, which is indicative of a positive movement towards employment equity. However, women only made up $16 \%$ of the senior management level in the same institution. In addition, the designated groups comprised $7 \%$ of the professionally qualified personnel who were experienced specialists, while the designated groups made up $20 \%$ of the academically qualified and skilled employees.

At the University of Pretoria, Africans (i.e. South African blacks) represented $30 \%$ of top management while other 
members of the designated groups were not represented. In addition, the designated groups in the University of Pretoria comprised only $10 \%$ of the professionally qualified and $31 \%$ of the academically qualified categories. However, white women alone in the University of Pretoria constituted $26 \%$ of academically qualified staff. The Witwatersrand University did not provide numbers of employees in the top management. Nevertheless, on further investigation it was found that whites made up $57 \%$ of senior management, whereas females at this level were exclusively white. In the professionally qualified band white males still dominated at $61 \%$, while $69 \%$ of females at this level were white (DoL, 2010).

\section{Conceptual Framework}

The study is located in the egalitarianism theory. Egalitarianism is one of the contemporary ultimate models that inspire diversity in social movements. The egalitarian point of view is that all members of the general public should receive equal treatment without exception (O'Leary, 2007). Islam, Merlo, Kawachi, Lindström, and Gerdtham (2006) affirm that egalitarianism is a concept that assumes different forms in social and political deliberations. Aspects of egalitarianism include economic, moral, legal, democratic, political, gender, and opportunity considerations. Among the notions that are critical for the study under review are equal opportunity, equity, employment equity and affirmative action. These pivotal concepts will now be discussed under separate headings.

\subsection{Equal opportunity}

In essence, equality of opportunity is promoted by creating favourable conditions for individuals to compete freely, "on a level playing field", for opportunities regardless of their background (Roemer, 2006). The criteria for selection should be based on talent rather than superfluous considerations (Gray \& Herr, 2006). Therefore, Blim (2005) affirms that equality of opportunity is the model that allows candidates to participate fruitfully in the economy and in the social sphere milieus.

Furthermore, equality of opportunity is an egalitarian concept that promotes meritocracy (Heywood, 1999). In a meritocratic society, people are judged on merit and satisfy the notion of similar remuneration for similar responsibility (Schmidtz 2006). In a meritocratic society, therefore, race and gender are immaterial and the emphasis is pinned on the state of being productive and competent (Swiff, 2001).

\subsection{Equity}

In South Africa equity is one of the underpinning constitutional principles entrenched in education policies. According to Cassim (2005) equity refers to techniques that are exploited to support equal opportunity and warrant fair treatment. One of the issues of fairness is that access ought to be based on ability and application, and not on factors such as ethnicity, gender or socio-economic status. Equity constitutes a fundamental obligation of the public system and signifies equality and social justice in society (Reimer, 2005). Therefore, equity remains a dominant subject that draws public attention and support (Wheeler 2002). In higher education the concept of equity signifies strategies and methods that are employed to afford access on all operating levels to the disadvantaged (Faakye, 2007).

\subsection{Employment Equity}

The implementation of EE is commonly regarded as a change strategy intended to avert and remedy discriminatory practices and improve representation in the workplace (Agocs \& Burr, 1996). It is not only focused on improving representation of the designated groups, but provides essential support and enhances the culture of the institution (Gultig, 2000). Affirmative action and EE are two different substitutable concepts. Human (1993) asserts that affirmative action is a vigorous process which is intended to support employment equity. Thus, EE is the consequence of both affirmative action and equal opportunity and will be achieved once employees' demographic profile reflects the composition of the national population in all branches and at all levels of employment (Meyer, 2002).

There are various barriers to the implementation of EE in institutions. Booysen (2007) lists the following:

- Slow introduction of employment equity at management level and inconsistent progress across departments;

- Low commitment to employment equity among top management;

- Fruitless consultation and communication on the progress and implementation of employment equity;

- Lack of cultural sensitivity displayed in dealing with new recruits (retention strategy);

- Lack of a culture that values diversity; 
- White male dominated institutional culture that is not inclusive, particularly where black recruits are concerned;

- No recognition of expertise, particularly where black recruits are concerned; and

- No systematic staff development and talent management.

Thus, employment equity implementation should be supported by adopting clear employment-practice strategies that are focused on career advancement, broad (inclusive) practices and the transformation of organisational culture.

\subsection{Affirmative Action}

Affirmative action and equal opportunity programmes serve as instruments to advance representation of the designated groups in the workplace. Affirmative action programmes were created to redress all forms of discrimination in the workplace, particularly in order to increase the numbers of the under-represented groups (McMillan-Capehart, Grubb, \& Herdman, 2009).

In short, affirmative action is the principal intervention strategy to eradicate all forms of discrimination and provide equal opportunities in the workplace. It is essential that barriers of discrimination be eradicated to allow those who were discriminated against to access employment of their choice, and to advance in their respective careers. One of the important characteristics of affirmative action is that it is temporary and flexible because its principal objective is to establish a suitable environment for equal opportunity.

\section{EE Legislation in South Africa}

In South Africa, the bases for legislation in support of equity policies are laid down in the Constitution, which include the fundamental right to equality as contained in the Bill of Rights. This right forms the basis for the above-mentioned EEA of 1998. However, the EEA is more particularly attributable to the Green Paper entitled "Employment and Occupational Equity", and to the EE Bill of 1997. Promulgation of the EEA was followed by the Skills Development Act of 1998.

As indicated in the introduction above, the present demographic profile in South African universities remains skewed, thus naturally raising the question whether sufficient progress has been made to correct the imbalance in racial composition. Universities struggle to retain academic staff from the designated groups since they are enticed by government departments and the private sector with lucrative remuneration. In addition, the difficulty is compounded by the rapid changes and insecurities in higher education institutions (Mkhwanazi \& Baijnath, 2003).

The DoE instituted the Ministerial Committee on Transformation and Social Cohesion and the Elimination of Discrimination in South Africa's Public Higher Education Institutions to investigate racial discrimination (DoE 2000). In responding to the report, Higher Education South Africa (HESA) (2010) acknowledged that transformation is a challenge facing every institution in the sector. The universities are cognizant of the importance of their role in promoting a culture of human rights among South Africans as the deciding factor in achieving the development and sustenance of democracy.

Mkhwanazi and Baijnath (2003) affirm that it is essential to investigate the progress made by higher education since the composition of staff is rather unrepresentative. After repealing discriminatory legislation South Africa will be duty-bound to equip sufficient numbers of competent individuals to compete for positions in both private and public occupations. Equitable representation that reflects the demographic realities in all employment is a required condition for a diverse society (Thaver, 2003).

\section{The Purpose of the Investigation}

It is clear from the above that the progress made by higher education institutions in creating equal opportunity and reflecting demographic realities in their staff composition should be investigated. Thus, the purpose of this research was to examine such progress and establish academic managers' views on factors that are important to the success of affirmative action and employment equity and the extent to which these factors contribute towards successful implementation of the process. The aim was also to develop a strategy for further action based on the deductions and discussions.

\section{Research Methodology}

The responsibilities borne by the academic managers who participated in the study were a key factor in selecting the survey design used for the purpose of the study. Some of the responsibilities of the academic managers include providing academic support to both lecturers and students, particularly in the interest of developing their respective departments, 
managing resources, supervising research activities, implementing their universities' policies and strategies, and addressing the problems students encountered daily in the course of their studies. In the light of the above the researchers opted for a survey design for a population that was rather too large to observe en masse. A survey design provides a quantitative or numeric description of trends, attitudes, or opinions of a population by studying a sample of that population (Creswell 2009).

A descriptive study was selected to determine the characteristics, opinions, attitudes and experiences of the population concerning the effectiveness of EE in their respective higher education institutions. According to Leedy and Ormord (2005), the researcher who conducts a descriptive study wants to determine how things are and wants to describe one or more characteristics of a fairly large population. In this situation, the researchers will, of course, usually not study the entire population at issue. Instead, the researchers select a sub-set, or sample, of that population. However, the researchers could use the results obtained from the sample to make generalisations about the entire population.

The academic staff members of Free State University, the Witwatersrand University and the University of Pretoria were considered the study population, and the Deans of Faculties, Directors of Schools and academic Heads of Departments were taken as the sample. The views of all the Deans, Directors and academic HOD's in each of the chosen universities were canvassed in view of their expertise and experience in managing their faculties, schools and departments which they represent in various strategic committees which make decisions about the effective operation of the various universities included in the survey. Cluster sampling was applied. As noted by Lehtonen and Pahkinen (2004), cluster sampling is popular because many populations are readily clustered into natural sub-groups. The academic HODs, the Directors and the Deans are already a cluster in higher education.

Data was collected by means of a questionnaire in order to minimize interruptions on the time of academic managers, who carry enormous responsibilities in leading and managing their respective departments and have hectic schedules. A questionnaire is the most widely used procedure for obtaining information for a variety of good reasons. For example, it is relatively economical, respondents can be reached in distant locations, the questions are standardised, anonymity can be assured, and questions can be coached to target a specific purpose (Opie, 2004).

Given the above, academic managers' perceptions of the effectiveness of EE in higher education were measured with particular reference to the following factors: institutional loyalty; personal reward; and progress towards employment equity. The questionnaire was structured according to these three criteria. Scale reliability testing and Cronbach alpha coefficients were used to validate the internal consistency reliability of these success factors, and the composite frequency tables were used to compare mean tests. Subjects were given a choice of three categories to rate their perceptions of the effectiveness of EE according to the success criteria. The categories were given as positive, average, and negative.

\section{Results}

The study applied frequency tables and the Statistical Analysis System (SAS) version 9.2 to analyse data. In addition, scale reliability testing was used to determine a form of reliability of the constructs used in the questionnaire to determine a rating for employment equity as a success factor. The type of reliability was referred to as internal consistency reliability, and a criterion to test whether sub-sets of questionnaire items which described a factor all truly contribute towards explaining the factor. Five tables were used and the first table determined the biographical properties of the respondents, including their managerial experiences. Table 2 demonstrates the scale reliability of the three sub-sets that are outlined in the purpose of the study. Table 3 presents the perceptions relating to institutional loyalty while Table 4 illustrates perceptions relating to personal rewards. Table 5 shows perceptions relating to progress towards EE. 
Table 1. Frequency Distributions of Biographical Properties of Respondents

\begin{tabular}{|c|c|c|c|c|}
\hline \multicolumn{5}{|c|}{$\begin{array}{l}\text { Frequency Distributions of the Four Biographical Properties of Respondents Probed in Section A of the Questionnaire } \\
\text { Gender (missing=2) }\end{array}$} \\
\hline Gender & Frequency & Percent & $\begin{array}{l}\text { Cumulative } \\
\text { Frequency }\end{array}$ & $\begin{array}{l}\text { Cumulative } \\
\text { Percent }\end{array}$ \\
\hline Male & 36 & 80.00 & 36 & 80.00 \\
\hline Female & 9 & 20.00 & 45 & 100.00 \\
\hline \multicolumn{5}{|c|}{ Population group (missing=3) } \\
\hline African & 5 & 11.36 & 5 & 11.36 \\
\hline Coloured & 1 & 2.27 & 6 & 13.64 \\
\hline White & 37 & 84.09 & 43 & 97.73 \\
\hline Indian & 1 & 2.27 & 44 & 100.00 \\
\hline \multicolumn{5}{|l|}{ Position (missing $=4$ ) } \\
\hline Executive Dean & 1 & 2.33 & 1 & 2.33 \\
\hline Dean & 4 & 9.30 & 5 & 11.63 \\
\hline Professor & 5 & 11.63 & 10 & 23.26 \\
\hline Director of School & 5 & 11.63 & 15 & 34.88 \\
\hline Head of Department & 28 & 65.12 & 43 & 100.00 \\
\hline \multicolumn{5}{|c|}{ Position Categories condensed (missing $=4$ ) } \\
\hline \begin{tabular}{|l|} 
Executive Deans/ \\
Dean/Prof/Directors
\end{tabular} & 15 & 34.88 & 15 & 34.88 \\
\hline Head of Department & 28 & 65.12 & 43 & 100.00 \\
\hline \multicolumn{5}{|l|}{ Years (missing=2) } \\
\hline$<1$ year & 10 & 22.22 & 10 & 22.22 \\
\hline $1-5$ years & 22 & 48.89 & 32 & 71.11 \\
\hline 6-10 years & 6 & 13.33 & 38 & 84.44 \\
\hline $11-15$ years & 3 & 6.67 & 41 & 91.11 \\
\hline $21-30$ years & 3 & 6.67 & 44 & 97.78 \\
\hline $30+$ years & 1 & 2.22 & 45 & 100.00 \\
\hline \multicolumn{5}{|c|}{ Years Categories condensed (missing $=2$ ) } \\
\hline$<1$ year & 10 & 22.22 & 10 & 22.22 \\
\hline $1-5$ years & 22 & 48.89 & 32 & 71.11 \\
\hline $5+$ years & 13 & 28.89 & 45 & 100.00 \\
\hline
\end{tabular}

Table 1 above demonstrates representation of the respondents and essentially illustrate gender and racial representation at various levels of management. The study considered it imperative to draw this picture before determining academic members' perceptions relating to employment equity. The table indicates that the total sample size was $45(\mathrm{~N}=45)$, which constitutes a relatively small sample from the target population of academic managers in the selected universities. The majority of the sampled respondents were male (80\%) and white (84\%). Sixty-five percent of the sampled respondents were HODs ( $\left.n_{1}=28\right)$, and the remaining 15 respondents were deans, executive deans, professors or directors of schools (these positions were jointly grouped as 'other managerial positions' in further analyses). The majority of respondents (71\%) had less than 6 years' experience in the same position, and the $29 \%$ with longer experience than 5 years were grouped into a category of 'more than 5 years' experience'. By comparing these properties of the sampled group to the corresponding properties of the target population, the researchers could determine whether the sample could be considered a representative group of the target population. The data from Table 1 confirmed that women are still severely under-represented, especially in senior management positions. 
Table 2. Scale Reliability Testing

\begin{tabular}{|l|c|c|c|c|}
\hline \multicolumn{4}{|c|}{ Scale Reliability Testing } \\
\hline Constructs & $\begin{array}{c}\text { Questionnaire items included } \\
\text { in the construct }\end{array}$ & $\begin{array}{c}\text { Items } \\
\text { omitted }\end{array}$ & $\begin{array}{c}\text { Standardized } \\
\text { Cronbach alpha }\end{array}$ & $\begin{array}{c}\text { construct score means } \\
\text { (Standard deviation) }\end{array}$ \\
\hline Institutional loyalty & $q 8-q 15$ & - & 0.95 & $2.67(0.86)$ \\
\hline Personal reward & $q 22-q 30$ & - & 0.92 & $2.56(0.80)$ \\
\hline Progress towards EE & $q 45-q 54$ & - & 0.94 & $2.34(0.81)$ \\
\hline
\end{tabular}

Scale reliability testing (see Table 2 above) was conducted on each of the three sub-sets of questionnaire item response ratings elicited from participating adolescents to verify the internal consistency reliability of each construct (or aspect) on employment equity. Each row presents the results of a separate analysis. Cronbach alpha values in the region of 0.70 (or greater than) can be regarded as indicators of internal consistency reliability. The values of all alpha coefficients were greater than 0.7 , which indicated internal reliability of all EE success factors. Measures of perceptions of successful implementation of aspects of Employment Equity - calculated as mean rating values for each sub-set of questionnaire item responses - can therefore be regarded as reliable measures of perception (a condition which has to be satisfied before calculated scores can be used to represent measures of perception).

Table 3. Institutional Loyalty

\begin{tabular}{|c|c|c|c|c|}
\hline \multicolumn{5}{|c|}{ Perceptions on Institutional Loyalty } \\
\hline \multirow{2}{*}{$\begin{array}{l}\text { Construct issues } \\
\text { Frequency, Percent, Row Pct. }\end{array}$} & \multicolumn{3}{|c|}{ Perception rating } & \multirow{2}{*}{ Total } \\
\hline & Positive & Average & Negative & \\
\hline \multirow{3}{*}{ Institution's trust in staff } & 32 & 7 & 5 & 44 \\
\hline & 8.99 & 1.97 & 1.40 & 12.36 \\
\hline & 72.73 & 15.91 & 11.36 & \\
\hline \multirow{3}{*}{ Institution's obligations towards staff } & 28 & 10 & 6 & 44 \\
\hline & 7.87 & 2.81 & 1.69 & 12.36 \\
\hline & 63.64 & 22.73 & 13.64 & \\
\hline \multirow{3}{*}{ Institution's recognition of staff } & 16 & 18 & 9 & 43 \\
\hline & 4.49 & 5.06 & 2.53 & 12.08 \\
\hline & 37.21 & 41.86 & 20.93 & \\
\hline \multirow{3}{*}{ Institution's commitment to staff wellness } & 17 & 18 & 10 & 45 \\
\hline & 4.78 & 5.06 & 2.81 & 12.64 \\
\hline & 37.78 & 40.00 & 22.22 & \\
\hline \multirow{3}{*}{ Institution's acknowledgement of staff's role in success } & 16 & 16 & 13 & 45 \\
\hline & 4.49 & 4.49 & 3.65 & 12.64 \\
\hline & 35.56 & 35.56 & 28.89 & \\
\hline \multirow{3}{*}{ Institution's role : knowledge desire } & 18 & 18 & 9 & 45 \\
\hline & 5.06 & 5.06 & 2.53 & 12.64 \\
\hline & 40.00 & 40.00 & 20.00 & \\
\hline \multirow{3}{*}{ Institution's role: staff growth } & 16 & 18 & 11 & 45 \\
\hline & 4.49 & 5.06 & 3.09 & 12.64 \\
\hline & 35.56 & 40.00 & 24.44 & \\
\hline \multirow{3}{*}{ Institution's mission and staff ideals } & 15 & 15 & 15 & 45 \\
\hline & 4.21 & 4.21 & 4.21 & 12.64 \\
\hline & 33.33 & 33.33 & 33.33 & \\
\hline Tral & 158 & 120 & 78 & 356 \\
\hline Total & 44.38 & 33.71 & 21.91 & 100.00 \\
\hline \multicolumn{5}{|l|}{$\begin{array}{l}\text { Frequency Missing }=20 \\
\text { Probability (Chi-square }=31.30)=0.005^{* * *}\end{array}$} \\
\hline
\end{tabular}

In the totals-row of Table 3 , the positive total (158 of 356 responses to all statements on this EE success factor - i.e. $44 \%$ ) in confirms the 2.67 score mean (approximately a ' 3 ', or average perceived performance rating) for the institutional loyalty score mean in Table 5 . The details of the table furthermore indicate that manager respondents actually only perceived the aspects of institutional trust in staff ( $73 \%$ positive responses) and institutional obligations towards staff 
(64\% positive responses) successfully implemented regarding the concept of institutional loyalty as a factor in successful $\mathrm{EE}$ implementation. The performances re EE for these two elements were statistically significantly more positively perceived than the other element of the construct.

Table 4. Personal Reward (Score Mean of 2.56)

\begin{tabular}{|c|c|c|c|c|}
\hline \multicolumn{5}{|c|}{ Perceptions on Personal Rewards } \\
\hline \multirow{2}{*}{\begin{tabular}{|l|} 
Construct Issues \\
Frequency, Percent, Row Pct.
\end{tabular}} & \multicolumn{3}{|c|}{ Condensed Perception rating) } & \multirow{2}{*}{ Total } \\
\hline & Positive & Average & Negative & \\
\hline \multirow{3}{*}{ Knowledge rewards } & 26 & 13 & 6 & 45 \\
\hline & 6.48 & 3.24 & 1.50 & 11.22 \\
\hline & 57.78 & 28.89 & 13.33 & \\
\hline \multirow{3}{*}{ Experience rewards } & 23 & 16 & 6 & 45 \\
\hline & 5.74 & 3.99 & 1.50 & 11.22 \\
\hline & 51.11 & 35.56 & 13.33 & \\
\hline \multirow{3}{*}{ Contribution rewards } & 25 & 13 & 7 & 45 \\
\hline & 6.23 & 3.24 & 1.75 & 11.22 \\
\hline & 55.56 & 28.89 & 15.56 & \\
\hline \multirow{3}{*}{ Expertise recognition } & 19 & 16 & 10 & 45 \\
\hline & 4.74 & 3.99 & 2.49 & 11.22 \\
\hline & 42.22 & 35.56 & 22.22 & \\
\hline \multirow{3}{*}{ Free, build career path } & 31 & 8 & 6 & 45 \\
\hline & 7.73 & 2.00 & 1.50 & 11.22 \\
\hline & 68.89 & 17.78 & 13.33 & \\
\hline \multirow{3}{*}{ HR: professional development, females } & 20 & 16 & 9 & 45 \\
\hline & 4.99 & 3.99 & 2.24 & 11.22 \\
\hline & 44.44 & 35.56 & 20.00 & \\
\hline \multirow{3}{*}{ Staff retention strategy, Affirmative action } & 15 & 16 & 12 & 43 \\
\hline & 3.74 & 3.99 & 2.99 & 10.72 \\
\hline & 34.88 & 37.21 & 27.91 & \\
\hline \multirow{3}{*}{ Staff retention strategy } & 11 & 21 & 11 & 43 \\
\hline & 2.74 & 5.24 & 2.74 & 10.72 \\
\hline & 25.58 & 48.84 & 25.58 & \\
\hline \multirow{3}{*}{ EE Awareness Campaign } & 17 & 21 & 7 & 45 \\
\hline & 4.24 & 5.24 & 1.75 & 11.22 \\
\hline & 37.78 & 46.67 & 15.56 & \\
\hline \multirow{2}{*}{ Total } & 187 & 140 & 74 & 401 \\
\hline & 46.63 & 34.91 & 18.45 & 100.00 \\
\hline \multicolumn{5}{|l|}{$\begin{array}{l}\text { Frequency Missing }=22 \\
\text { Probability (Chi-square }=28.26)=0.03^{*}\end{array}$} \\
\hline
\end{tabular}

In the totals-row of Table 4, the positive total (187 of 401 responses to all statements on this EE success factor - i.e. 47\%) confirms the almost average perceived performance rating score mean of 2.56 (approximately a ' 3 ' average performance rating) for the personal reward score mean in Table 2. The details of the table furthermore indicate that manager-respondents perceived the successful EE implementation-performance of especially the elements of free to build one's own career path (69\%) and valuation of staff contributions (56\%) positively. EE performance re Expertise recognition, and staff retention strategies were rated rather average to negative. 
Table 5. Progress towards EE (Score Mean of 2.34)

\begin{tabular}{|c|c|c|c|c|}
\hline \multicolumn{5}{|c|}{ Perceptions on Progress towards Employment Equity } \\
\hline \multirow{2}{*}{$\begin{array}{l}\text { Construct Issues } \\
\text { Frequency, Percent, Row Pct. }\end{array}$} & \multicolumn{3}{|c|}{ Perception rating } & \multirow{2}{*}{ Total } \\
\hline & Positive & Average & Negative & \\
\hline \multirow{3}{*}{ EE commitment, senior management } & 34 & 5 & 5 & 44 \\
\hline & 7.83 & 1.15 & 1.15 & 10.14 \\
\hline & 77.27 & 11.36 & 11.36 & \\
\hline \multirow{3}{*}{ Senior management opportunities, women } & 34 & 4 & 6 & 44 \\
\hline & 7.83 & 0.92 & 1.38 & 10.14 \\
\hline & 77.27 & 9.09 & 13.64 & \\
\hline \multirow{3}{*}{ Changed culture for EE } & 25 & 12 & 6 & 43 \\
\hline & 5.76 & 2.76 & 1.38 & 9.91 \\
\hline & 58.14 & 27.91 & 13.95 & \\
\hline \multirow{3}{*}{ EE institutional communication channels } & 24 & 15 & 5 & 44 \\
\hline & 5.53 & 3.46 & 1.15 & 10.14 \\
\hline & 54.55 & 34.09 & 11.36 & \\
\hline \multirow{3}{*}{ EE strategic plan } & 29 & 7 & 7 & 43 \\
\hline & 6.68 & 1.61 & 1.61 & 9.91 \\
\hline & 67.44 & 16.28 & 16.28 & \\
\hline \multirow{3}{*}{ Staff, EE-implementation } & 27 & 11 & 5 & 43 \\
\hline & 6.22 & 2.53 & 1.15 & 9.91 \\
\hline & 62.79 & 25.58 & 11.63 & \\
\hline \multirow{3}{*}{ Management feedback, EE progress } & 31 & 6 & 6 & 43 \\
\hline & 7.14 & 1.38 & 1.38 & 9.91 \\
\hline & 72.09 & 13.95 & 13.95 & \\
\hline \multirow{3}{*}{ HR support, professional development of woman } & 27 & 10 & 6 & 43 \\
\hline & 6.22 & 2.30 & 1.38 & 9.91 \\
\hline & 62.79 & 23.26 & 13.95 & \\
\hline \multirow{3}{*}{ Retention strategy for Affirmative action } & 16 & 18 & 10 & 44 \\
\hline & 3.69 & 4.15 & 2.30 & 10.14 \\
\hline & 36.36 & 40.91 & 22.73 & \\
\hline \multirow{3}{*}{ Functionality, EE awareness } & 15 & 18 & 10 & 43 \\
\hline & 3.46 & 4.15 & 2.30 & 9.91 \\
\hline & 34.88 & 41.86 & 23.26 & \\
\hline \multirow{2}{*}{ Total } & 262 & 106 & 66 & 434 \\
\hline & 60.37 & 24.42 & 15.21 & 100.00 \\
\hline
\end{tabular}

In the totals-row of Table 5, the positive total (262 of 434 responses to all statements on this EE success factor - i.e. $60 \%$ ) confirms the approximately positive perceived performance rating score mean of 2.34 (close to a ' 2 ' positive performance rating) for the progress towards the EE score mean in Table 2. Manager-respondents perceived the performance of the elements of retention strategy for academics and designated groups, and the functionality of $E E$ awareness campaigns statistically significantly less positive than the other elements of the progress towards the $E E$ concept.

\section{Discussion}

On the basis of the results it can be concluded that the demographic composition of staff in higher education institutions fails to reflect the demographic realities of South Africa so that black people and women are still severely underrepresented, especially in senior academic management positions. White males still dominate senior management positions in the selected universities; white males and females dominate professionally qualified and academically qualified positions in the selected institutions; white women are sufficiently represented as compared to women from the designated groups; and the greatest numbers of the designated groups' members were in the unskilled categories in the selected universities. Most of the respondents had less than six years' experience in the same position. Perceptions of 
employee loyalty were highly positive. This confirms that academic managers are committed to their jobs and loyal to their institutions.

The respondents indicated trust in their colleagues of all races as positive. They recorded a similar response in the matter of supporting the university's commitment to achieving EE. The respondents recorded positive responses in their ratings of institutional trust in staff and institutional obligations towards staff. The respondents indicated positive attitudes in their ratings of successful EE implementation on the basics that they were free to build their own career path and the universities valued staff contributions. However, EE performances on expertise recognition and staff retention were rated average to negative. The respondents indicated less positive responses to the issue of retaining academic staff from the designated groups and functionality of an EE awareness campaign against the other elements of progress towards $\mathrm{EE}$ concepts. Lastly, the Heads of Departments perceived EE performance to be statistically less positive than other managerial positions.

The need to achieve a more demographically representative staff profile in higher education institutions in South Africa is gaining urgency. Rectifying white male domination will require proficient leadership, particularly from top management. Top management should develop an EE strategy with a feasible action plan in consultation with the university stakeholders, and it is important that the EE strategy be integrated with the existing university strategy. This will ensure that EE remains in sync with programmes that are integral to the univeristy's operational programmes. It should be the responsibility of top management, particularly the vice-chancellor, to ensure that the goals set in the action plan are met and responsible individuals who are assigned to various tasks are accountable. Having sound policies on EE is tantamount to a fishing expedition if there is no successful implementation.

One of the fundamental values of any institution is the ability to recognise the expertise of its own members. Such recognition inspires a sense of institutional belonging, of being part of the university. Members feel appreciated and valued. Since EE is rather a complex phenomenon, recognition of expertise will encourage the development and expression of a variety of perspectives and thus be conducive to successful implementation of employment equity. A culture of an institution that embraces and appreciates diversity and acknowledges that every individual is unique inspires people to accept one another. Being able to accept one another is a rewarding virtue that empowers people to tolerate one another. Since universities are fertile breeding grounds from which to shape society they should vigorously seek to promote a culture of tolerance that will spill over into society at large.

Prosperity in any institution depends on its capability to retain knowledgeable staff members. Universities urgently need to develop realistic retention strategies that will stand them in good stead in terms of continuity that will enable them to make seamless, uninterrupted progress. Human-resource departments should play a leading role in developing retention strategies since it is one of their responsibilities to safeguard the welfare of employees. Staff members should be interviewed on a regular basis to determine their state of mind with a view to taking prompt remedial measures where necessary. Staff turnover remains a thorny subject in every institution. The lack of retention strategies will most certainly hinder the significant progress made so far by the selected universities.

The initiatives taken to gain representation and appreciation for white females demonstrate the positive factors of employment equity. By the same token, it is noted with concern that black females are still under-represented. The initiatives to recruit white females should be extended to black females. Merely selecting members of the designated groups in preference to others is certainly no guarantee in itself that EE will be implemented successfully. Ultimately the staff composition in the universities should reflect the demographic realities of South African society.

Communication is the lifeblood of every institution. It is an instrument that permeates all the ramifications of the institution. No matter how brilliant the strategy employed to achieve employment equity, if key stakeholders are not informed, the strategy will remain another fishing expedition. Once all staff members are consulted on EE or policy, it is important for the university to outline and initiate vigorous awareness campaigns. This is a platform to keep everyone on the same page. If every staff member irrespective of race is conversant with the prospects of employment equity, they will be able to make meaningful contributions in their respective departments.

Since HODs are amongst the main implementers of $E E$ it is significant that they express doubt about the effectiveness of endeavours to implement EE. HODs certainly need to be part of the employment strategy development, and must be fully involved. They should be held accountable for the implementation of EE in their respective departments. They should be the cluster that advises members of staff in their various departments about the prospects and developments of employment equity. Periodic feedback on initiatives to implement $E E$ is essential as a means to discover underperformances and advances. HODs, Directors of Schools, and Deans of Faculties should take it upon themselves collectively to steer the process of transformation at the university. In order to address the purpose of this study namely to establish academic managers' views on factors that are important building blocks for the success of affirmative action and the implementation of employment equity, and also to establish the extent to which these factors 
contribute towards successful implementation of the process, the instrument below can be used by universities to measure the effectiveness of endeavours to implement employment equity.

As indicated below, an EE strategy requires visionary leadership. Developments relating to $\mathrm{EE}$, diversity management, and retention strategies should be brought home vigorously to the university community. Communication develops a sense of belonging and feedback is vital. Lastly, synergy among members of a proficient leadership, employment equity, diversity management, retention strategy, and communication will lead to achievement of full-ledged EE.

Figure 1: Employment Equity Strategy

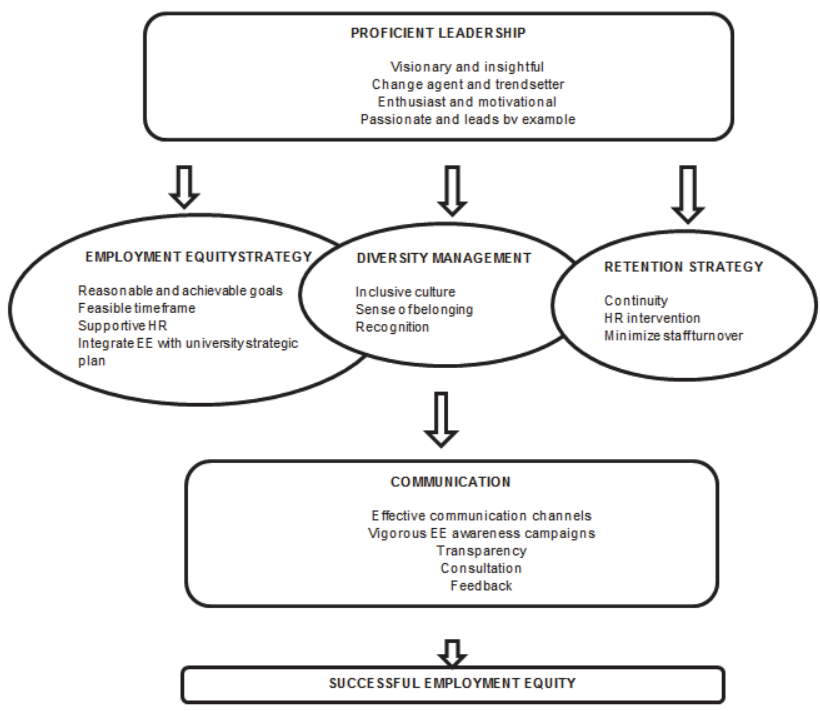

\section{Conclusion}

An EE strategy could be the foundation stone of a conducive environment for healthy competition amongst competent personnel in the workplace. Given that academics are regarded as the most rational, open-minded scholars in society, they are morally obliged to pursuade society at large to embrace change, which should therefore begin in the university settings. Affirmative action is the primary remedial strategy to eliminate all forms of inequalities in the workplaces and to allow those who were discriminated against to come into their own. EE is relatively new concept with similar purpose to affirmative action. Finally, as noted earlier, the staff composition in the workplace, including higher education institutions must eventually reflect the demographic realities of South African society.

\section{Acknowledgement}

We thank Helene Muller (Research Support Consultant, ITC Research Support Unit, University of South Africa) who did the statistical analysis for this research.

\section{References}

Agocs, C., \& Burr, C.(1996). Employment equity, affirmative action and managing diversity: assessing the differences. International Journal of Manpower , 17(4/5), 30-45.

Blim, M. (2005). Equality and economy: the global challenge. Lanham: Rowman \& Littlefield Publishers, Inc.

Booysen, L. (2007). Barriers to implement equity implementation and retention of Blacks in management in South Africa. Journal of Labour Relations, 31(1), 47-71.

Cassim, S. (2005). Reflections on equity and diversity at higher education institutions in South Africa. South African Journal for Higher Education, 14(4), 653-665. 
Creswell, J. W. (2009). Research design, qualitative, quantitative and mixed methods approaches. Thousand Oaks: SAGE Publications.

Department of Education. (1997). Education White Paper 3. A programme for Higher Education Transformation. Pretoria: Government Gazette Printers.

Department of Education. (2000). Towards a new higher education landscape: meeting the equity, quality and social development imperatives of South Africa in the 21st century. Pretoria: Government Gazette Printers.

Department of Labour. (2010). Commission for Employment Equity Annual Report 2009-2010. Pretoria: Government Printers.

Faakye, S. (2007). Equity policies in higher education, a legal evaluation of institutional response. Unpublished thesis. Master of Philosophy. University of Oslo, June 21.

Gray, K. C., \& Herr, E. L. 2006. Other ways to win: creating alternatives for high school graduates, $3^{\text {rd }}$ ed. California: Corwin Press.

Gultig, J. (2000). The university in post-apartheid South Africa: new ethos and new divisions, South Africa Journal for Higher Education, 14(1), 37-24

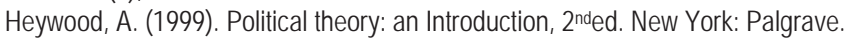

Higher Education South Africa (HESA), (2010).Insight higher education South Africa. Pretoria: HESA Publications.

Human, L. (1993). Affirmative action and development of people, a practical guide. Kenwyn: Juta and Company, Ltd.

Islam, M. K., Merlo, J., Kawachi. I., Lindström. M., \& Gerththam, G. (2006). Social capital and health: does egalitarianism matter? International Journal for equity in health, 5(3), 1-28.

Leedy, P. D., \& Ormord, J.E. (2005). Practical research planning and design. $8^{\text {th }}$ ed. New Jersey: Merrill Practice.

Lehtonen, R. D., \& Pahkinen, E. (2004). Practical methods for design and analysis of complex surveys. $2^{\text {nd }}$ ed. Chichester: John Wiley \& Sons, Ltd.

McMillan-Capehart, A., Grubb, W.L., \& Herdman, A. (2009). Affirmative action decisions: when ignorance is bliss. Equal Opportunities International, 28(5), 415-431.

Meyer, M. (2002). Managing human resource development: an outcomes-based approach. $2^{\text {nd }}$ ed. Durban: LexisNexis Butterworth.

Mkhwanazi, V., \& Baijnath, N. (2003). Equity development programmes for academic staff at South African High Education Institutions: progress and promise South African Journal of Higher Education, 179(3), 106-113.

Ntshoe, I.M. (2003). The political economy of access and equitable allocation of resources to higher education. International Journal of Education Development, 23(4), 381-398, July.

O'Leary, Z. (2007). The social science jargon buster, the key terms you need to know. Los Angeles: Sage Publications.

Opie, C. (2004). Doing your educational research: a guide for first time researchers. London: SAGE Publications.

Portnoi, L. (2009). Transformative change? Instructional formalities and Instructional realities, South African Journal on Higher Education, 23(2), 373-385.

Ramrathan, P., Manik, .S, \& Pillay,A. (2007). Transformation access: the upward Bound Programine as a possibility for promising access to Higher Education. South African Journal on Higher Education, 21(4), 733-752.

Reimer, A. (2005). Equity in public education. Manitoba Association of School Superintendents, 2(1), 1-6.

Roemer, J. E. (2006). Democracy, education, and equality: Graz Schumpeter Lectures. Melbourne: Cambridge University Press.

Schmidtz, D. (2006). Elements of justice. New York: Cambridge University Press

Swiff, A. (2001). Political philosophy: a beginner's guide for students and politician. Cambridge: Polity Press.

Thaver, B.(2003). Deracialising Universities, reflexive conversations. South African Journal for Higher Education, 17(3), $144-151$.

Thomas, A. (2003). Employment Equity Practices at selected companies in South Africa. South African Journal of Labour Relations, 27(2), 6-12.

Wheeler, K. G. (2002). Cultural values in relation to equity sensitivity within and across cultures. Journal of Management Psychology, $17(2), 612-627$. 